\title{
Evaluation of Montreal cognitive assessment for the differential diagnosis of mild cognitive impairment and Alzheimer's disease in elderly patients with more than 5 years of schooling: Data from a Brazilian sample
}

\author{
José M. Montiel ${ }^{1^{*}}$, Juliana F. Cecato ${ }^{2}$, Daniel Bartholomeu ${ }^{1}$, José Eduardo Martinelli ${ }^{2}$ \\ ${ }^{1}$ FIEO University Center, Osasco, Brazil; ${ }^{*}$ Corresponding Author: montieljm@hotmail.com \\ ${ }^{2}$ Jundiai Medical School, Jundiaí, Brazil
}

Received 29 May 2013; revised 29 June 2013; accepted 7 July 2013

Copyright (C) 2013 José M. Montiel et al. This is an open access article distributed under the Creative Commons Attribution License, which permits unrestricted use, distribution, and reproduction in any medium, provided the original work is properly cited.

\section{ABSTRACT}

Background: Diagnostic investigation of dementia is based on a series of tests which lie the neuropsychological evaluations. The Montreal Cognitive Assessment (MoCA) was developed as an instrument to recognize Mild Cognitive Impairment $(\mathrm{MCl})$ and initial cases of Alzheimer's disease. The present study aims to evaluate the predictive value of Brazilian MoCA test version in a sample of elderly above 5 years of education. Methods: Cross-sectional study with 136 elderly, above 60 years old at least 5 years of education. Diagnostic criteria is based on clinical and neuropsychological data classified Alzheimer's disease $n=52, \mathrm{MCl} n=45$ e normal controls $n=39$. MoCA test was compared with Cambridge Cognitive Examination, Mini-Mental State Exam, Verbal Fluency, Clock Drawing Test, Geriatric Depression Scale and Pfeffer Functional Activities Questionnaire. Accuracy was evaluated by receiver operating characteristic (ROC) curve analyses. Pearson correlation coefficient was used to compare the MoCA with the other tests. It was also used logistic regression analysis to identify the main risk factors for the diagnostic groups. Results: MoCA was the best test to differentiate Alzheimer's disease cases from $\mathrm{MCl}$ with $86.5 \%$ sensitivity and $75.6 \%$ specificity. Furthermore, analyzes of correlation test showed that MoCA correlates robust way of already validated with other tests and wide application in Brazil. Conclusions: It can be concluded that MoCA is a good screening tool for investigation of $\mathrm{MCl}$ among the elderly in Brazil with over 5 years of schooling. Studies with larger numbers of participants are needed to further validate the test also for elderly people with low education.

Keywords: Elderly, MoCA; Mild Cognitive Impairment; Alzheimer's Disease;

Neuropsychological Tests

\section{INTRODUCTION}

Aging is a process where significant losses occur in physical and cognitive abilities of the individual and those changes do not interfere with the functionality to perform their activities [1,2]. Some of the cognitive losses are not compatible with normal aging and can be related to demential diseases that also have an evolution.

In spite of the forgetfulness for recent events are an early diagnostic sign for Alzheimer's disease (AD) [3-7], declines in memory established by neuropsychological assessment (according to age and educational level) that does not interfere with basic activities (ADL) and instrumental (IADL's) daily life give rise to a new construct, called Mild Cognitive Impairment (MCI) [8-12]. $\mathrm{MCI}$ is an important target of recent research because it can increase the probability of the clinical frame evolute to dementia. Hence, MCI is considered as a transitional phase between the cognitive decline and dementia [1316]. Petersen (2001) suggests a conversion rate of 10 to $15 \%$ of MCI that progresses to AD.

International Classification of Disease (ICD-10) addresses the issue of cognitive impairment in order to 
differentiate this condition from demential frame and suggests some features to characterize them such as: a) the general criteria for other disorders must not be satisfied; b) change in cognitive function (memory, attention, concentration, language, etc.) for at least two weeks, reported by the patient or informant; c) this decline must be present in neuropsychological; and d) should not be met criteria for another disorder or dementia $[17,18]$.

The diagnostic criteria of MCI referring to memory decline and/or other cognitive functions (performance on cognitive tests must be less than one standard deviation below when compared to patients with the same age and education), not having difficulties in performing functional daily living activities and does not meet the diagnostic criteria for dementia [19-21]. In April 2011, the National Institute on Aging and Alzheimer's Association published recommendations for the diagnostic criteria of the MCI such as evidence of cognitive impairment (proven in psychological testing and confirmed by an informant or family with daily contacting with the patient) $[22,23]$. Furthermore, there may be impairment in one or more cognitive domains (such as attention, concentration, executive function, etc.), nevertheless preserving the functional abilities and cognitive changes should be mild and not necessarily indicate dementia. All these changes are considered in addition to clinical history and also levels of education and patient age. MoCA test is a brief screening instrument that evaluates a range of cognitive functions (executive function, visuospatial, naming, memory recall, attention, language, abstract thought and orientation), necessary aspects for the MCI and dementia diagnosis [24-29]. The estimated test time of application is about 20 minutes, the maximum score is 30 points, and the cutoff for MCI is 26 points and a score above 26 is considered normal testing. Furthermore, it should be considered in the interpretation of the final score of this test, the educational level of the patient. These cutoff points are related to patients with less than 12 years of educational level [24]. Hence, the present study aims to evaluate the predictive value of Brazilian MoCA test version for the Differential Diagnosis of Mild Cognitive Impairment and Alzheimer's disease in a sample of elderly with less than 5 years of education.

\section{METHODS}

\subsection{Participants}

The cross-sectional study involved 136 elderly treated at the Institute of Geriatrics and Gerontology Jundiai, aged above 60 years, of both sexes and with at least 5 years of schooling.

The diagnostic criteria for dementia were based on
DSM-IV criteria for Alzheimer's disease in the NINDSADRDA [16] and performed by a Gerontologist. For the diagnosis of MCI Petersen (2001) criteria were considered. The inclusion criteria for the elderly normal controls (NC) group were patients who score above the cutoff point on neuropsychological tests, have no symptoms of dementia, GDS score of less than 6 and not have commitment to perform activities of daily living. After clinical evaluation and neuropsychological assessment, a patient informant or a family member with daily contact were interviewed to report possible symptoms or relevant information about behavioral changes. The patients participated in the survey own free will, according to the Research Ethics Committee approval $54 / 2011$.

From the total of 136 participants, 52 elderly $(38.2 \%)$ received a diagnosis of Alzheimer's disease, 45 (33.1\%) of Mild Cognitive Impairment and 39 elderly (28.7\%) were part of the NC. It was found that the vast majority corresponded to females, $89(65.4 \%)$ women, and the average age was equal to 75.74 years $(\min =60, \max =$ 92 , standard deviation $[\mathrm{SD}]=7,38$ ). The sample has a higher number of elderly people with high educational levels, with 80 participants $(58.8 \%)$ with over 9 years of study.

\subsection{Instruments and Analysis Procedures}

All patients undergone detailed clinical history and neuropsychological assessment. The applied neuropsychological tests were: Cambridge Cognitive Examination (CAMCOG) (Roth, 1986), Mini-Mental State Examination (MMSE) [11], Clock Drawing Test (CDT) Mendez (1992) and Shulman (1993) scale, MoCA Brazilian version [29], Verbal Fluency Test (VF) [6], Geriatric Depression Scale (GDS) shortened 15-item [29] and Pfeffer Functional Activities Questionnaire (PFAQ) [25].

Categorical variables and the scores evaluated according to the best cut-off points (established by the ROC curve) were studied by the chi-square or Fisher exact test. Logistic regression was performed based on cutoff points of the ROC curve with variable selection criterion stepwise. The dependent variables were the risk factors for $\mathrm{AD}$ studied in relation to MCI (independent variable).

\section{RESULTS}

Analyzes were performed by means of ROC curve (receiver operating characteristic) and the results show that the highest value of AUC (Area Under the Curve) was founded in MoCA. In other words, MoCA test is the most effective to differentiate the groups MCI from NC. The sensitivity and specificity was equal to $82.2 \%$ and 92.3\%, respectively (Tables 1 and 2, Figure 1). We 
compared the sensitivity and specificity values of MoCA test with other tests. It appears that the MoCA was different from GDS, the TDR Mendez and Shulman' scale, with significantly different sensitivity. The MoCA was the best test capable of differentiating MCI from NC.

The same test was important to differentiate the $\mathrm{NC}$ from AD group, with $98.1 \%$ sensitivity and $100 \%$ specificity (Table 3, Figures 2 and 3). We also compared the values of the sensitivities and specificities of MoCA test with other tests. We observed that MoCA was different from all the other tests, with significantly different sensitivity (being the MoCA, the largest) and higher specificity. In other words, MoCA is superior to other instruments in differentiating AD from NC.

To be considered a transitional phase for dementia, MCI has been the target of numerous studies where the main objective is to find an effective test for differentiating patients with $\mathrm{AD}$ from MCI. Results showed MoCA was the instrument with the highest AUC, with $82.9 \%$ sensitivity and $75.6 \%$ specificity (Table 4 ). It can be inferred from the presented data that for elderly with more than 5 years of educational level, MoCA has better diagnosis accuracy in differentiating $\mathrm{MCI}$ and $\mathrm{AD}$ from NC. It is observed that MoCA was different from all the other tests (except PFAQ), showing sensitivity statistically different from the mentioned (being the MoCA, the largest) and/or higher specificity, and the MoCA higher than others in differentiating AD from MCI. The analysis showed that MoCA cutoffs points presented to differentiate the diagnostic groups were: a score below 21 points for $\mathrm{AD}$ and greater than 21 points for MCI. The cutoff point that distinguishes $\mathrm{MCI}$ from NC was 25.

That done, we performed a multiple logistic regression analysis adopting the stepwise selection variables method, considering the following independent variables: education, age, MoCA, CAMCOG, MMSE, Mendez,

Table 1. Characteristics between diagnostic groups with respect to age, gender and education.

\begin{tabular}{ccccc}
\hline & NC & MCI & AD & $\boldsymbol{p}$ \\
\hline Age (years) & $71.82( \pm 6.89)$ & $76.60( \pm 7,06)$ & $77.92( \pm 6.97)$ & ${ }^{*} 0.185$ \\
Gender & & & & \\
Female & $74.4 \%$ & $60 \%$ & $63.5 \%$ & ${ }^{* *} 0.358$ \\
Male & $25.6 \%$ & $40 \%$ & $36.5 \%$ & \\
$\begin{array}{c}\text { Education } \\
\text { Group 1: } 5 \text { to } 8 \\
\text { years }\end{array}$ & $30.8 \%$ & $51.1 \%$ & $40.4 \%$ & ${ }^{* *} \mathbf{0 . 0 4 0}$ \\
$\begin{array}{c}\text { Group 2: }>9 \\
\text { years }\end{array}$ & $69.2 \%$ & $48.9 \%$ & $59.6 \%$ & \\
\hline $\begin{array}{c}* \\
p=\text { t de student; }{ }^{* *} p=x^{2} .\end{array}$ & & & \\
\hline
\end{tabular}

Shulman, GDS, PFAQ, VF animals, fruits and words with the letter "M". The dependent variables were diagnostic group of $\mathrm{AD}$ and $\mathrm{MCI}$ in order to identify the main factors that can identify and separate these groups.

We identified that elderly with MoCA $<21$ points is 15.4 times more likely to have AD than MCI, PFAQ scores $\geq 6$ points is 8.1 times more likely to MCI than AD and verbal fluency (animals version) scores $\leq 14$ points is 5.2 times more likely to MCI than DA (Table 5). In other terms, for differential diagnoses we suggest that, for people with over 5 years of schooling, subjective memory complaint coupled with evidence of cognitive decline in MoCA and the verbal fluency test animals version, in addition to activities of daily living impairment, separate cases of dementia (AD) from MCI.

\section{DISCUSSION}

The MoCA test has been validated for the Portuguese in preliminary studies with 14 patients with individuals aged between 52 and 78 years [28,29]. The Brazilian version showed good psychometric properties and significant capacity to differentiate cases of MCI from AD and normal controls [12]. The Arabic version found a sensitivity of $92.3 \%$ and specificity of $85.7 \%$ for the MCI [27]. A Taiwanese version made with 207 seniors showed a cutoff of 23/24 points for the MCI, with good sensitivity and specificity of $92 \%$ and $78 \%$ respectively [29]. A recent study by Freitas (2011) was compared to the predictive value of MoCA and MMSE in the diagnosis of AD. The results showed that the test MoCA showed greater ability to predict $\mathrm{MCI}$ and $\mathrm{AD}$ frames compared to MMSE. In this study, it was established a 17 cutoff point for $\mathrm{AD}$ and 22 points for MCI. Both studies by Freitas (2011) and Tsai (2011) concluded that MoCA is a more precise instrument with better psychometric properties when compared to MMSE with high sensitivity and specificity for both MCI and to AD diagnosis.

In our research the best result of MoCA in the differential diagnosis between the three groups in question (NC, MCI and AD) is highlighted the role of education. Clearly the number of study years provides a cognitive reserve that acts as a protective mechanism of dementia and affects performance on cognitive tests. According to Parente (2009) and Nitrini (2009), schooling influences cognition performance in elderly, what corroborates the results of this research where the highest percentage of high educational level (over 9 years) was found in NC (individuals without cognitive impairment).

Considering MoCA test, data from this survey showed that the majority of their items can differentiate the three diagnostic groups. MoCA was developed as an assessment tool for MCI diagnostic and mild cases of dementia 
Table 2. Cutoffs created by BOW ROC methodology to differentiate between MCI and NC.

\begin{tabular}{|c|c|c|c|c|c|c|c|c|}
\hline \multirow{3}{*}{ MOCA } & \multirow{2}{*}{$\begin{array}{c}\text { MCI } \\
\mathbf{n}\end{array}$} & \multirow{2}{*}{$\frac{\mathrm{NC}}{\mathrm{n}}$} & \multirow{2}{*}{\multicolumn{2}{|c|}{$\begin{array}{c}\text { Sensibility } \\
\text { IC } 95 \%\end{array}$}} & \multirow{2}{*}{\multicolumn{2}{|c|}{$\begin{array}{c}\text { Specificity } \\
\text { IC } 95 \%\end{array}$}} & \multirow{2}{*}{ AUC } & \multirow{2}{*}{$p$} \\
\hline & & & & & & & & \\
\hline & & & & & & & & $<\mathbf{0 . 0 0 0 1}$ \\
\hline$<25$ & 37 & 3 & \multicolumn{2}{|c|}{$82.2 \%$} & \multicolumn{2}{|c|}{$92.3 \%$} & 0.943 & \\
\hline$\geq 25$ & 8 & 36 & $71.1 \%$ & $93.4 \%$ & $83.9 \%$ & $100.0 \%$ & & \\
\hline CAMCOG & $\mathrm{n}$ & $\mathrm{n}$ & & & & & & $<0.0001$ \\
\hline$<92$ & 30 & 4 & \multicolumn{2}{|c|}{$66.7 \%$} & \multicolumn{2}{|c|}{$89.7 \%$} & 0.8621 & \\
\hline$\geq 92$ & 15 & 35 & $52.9 \%$ & $80.4 \%$ & $80.2 \%$ & $99.3 \%$ & & \\
\hline GDS & $\mathrm{n}$ & $\mathrm{n}$ & & & & & & 0.2044 \\
\hline$\geq 2$ & 27 & 18 & \multicolumn{2}{|c|}{$60.0 \%$} & \multicolumn{2}{|c|}{$53.8 \%$} & 0.5729 & \\
\hline$<2$ & 18 & 21 & $45.7 \%$ & $74.3 \%$ & $38.2 \%$ & $69.5 \%$ & & \\
\hline MMSE & $\mathrm{n}$ & $\mathrm{n}$ & & & & & & $<0.0001$ \\
\hline$<29$ & 36 & 7 & \multicolumn{2}{|c|}{$80.0 \%$} & \multicolumn{2}{|c|}{$82.1 \%$} & 0.8322 & \\
\hline$\geq 29$ & 9 & 32 & $68.3 \%$ & $91.7 \%$ & $70.0 \%$ & $94.1 \%$ & & \\
\hline Mendez & $\mathrm{n}$ & $\mathrm{n}$ & & & & & & 0.0049 \\
\hline$<20$ & 30 & 14 & \multicolumn{2}{|c|}{$66.7 \%$} & \multicolumn{2}{|c|}{$64.1 \%$} & 0.6781 & \\
\hline$\geq 20$ & 15 & 25 & $52.9 \%$ & $80.4 \%$ & $49.0 \%$ & $79.2 \%$ & & \\
\hline PFAQ & $\mathrm{n}$ & $\mathrm{n}$ & & & & & & $<0.0001$ \\
\hline$\geq 1$ & 34 & 9 & \multicolumn{2}{|c|}{$75.6 \%$} & \multicolumn{2}{|c|}{$76.9 \%$} & 0.7752 & \\
\hline$<1$ & 11 & 30 & $63.0 \%$ & $88.1 \%$ & $63.7 \%$ & $90.1 \%$ & & \\
\hline Shulman & $\mathrm{n}$ & $\mathrm{n}$ & & & & & & 0.0045 \\
\hline$<5$ & 29 & 13 & \multicolumn{2}{|c|}{$64.4 \%$} & \multicolumn{2}{|c|}{$66.7 \%$} & 0.6658 & \\
\hline$\geq 5$ & 16 & 26 & $50.5 \%$ & $78.4 \%$ & $51.9 \%$ & $81.5 \%$ & & \\
\hline
\end{tabular}

AUC $=$ area under the curve. chi-square $/{ }^{*}$ Fisher's exact test.

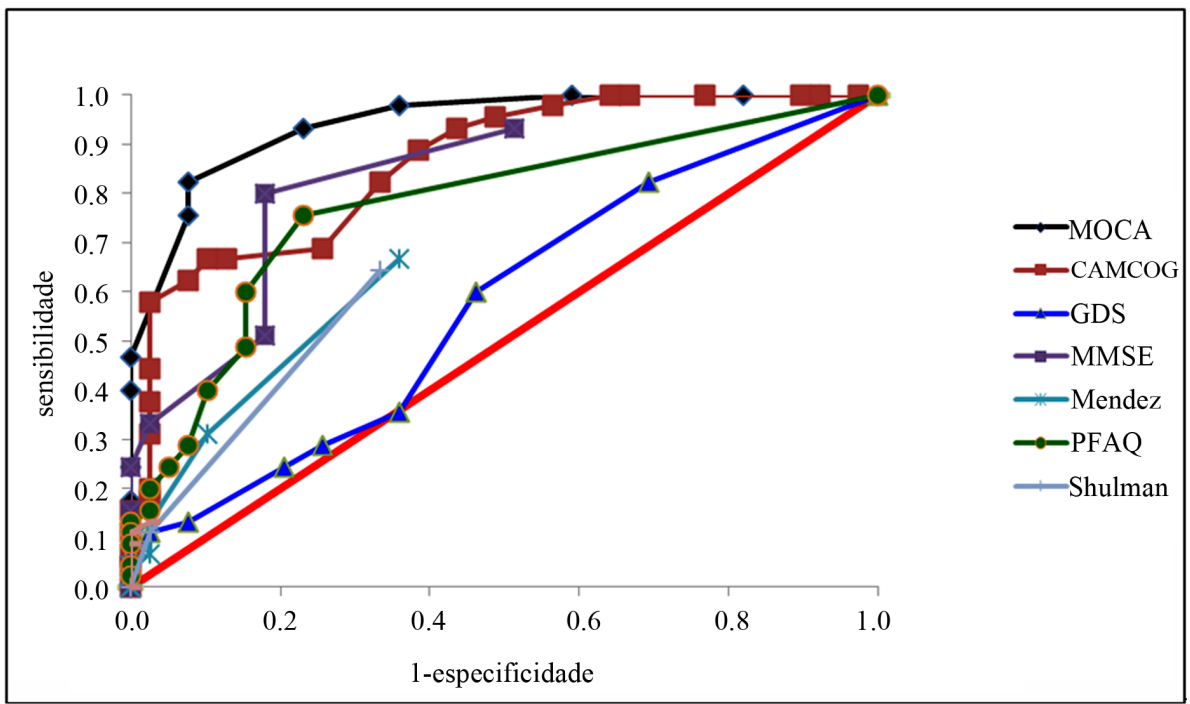

Figure 1. ROC curve to identify MCI from NC. 
Table 3. Cutoffs created by BOW ROC methodology to differentiate between AD and NC.

\begin{tabular}{|c|c|c|c|c|c|c|c|c|}
\hline \multirow{2}{*}{ MOCA } & \multirow{2}{*}{$\frac{\text { AD }}{n}$} & \multirow{2}{*}{$\frac{\mathrm{NC}}{\mathrm{n}}$} & \multirow{2}{*}{\multicolumn{2}{|c|}{$\begin{array}{c}\text { Sensibility } \\
\text { IC } 95 \%\end{array}$}} & \multirow{2}{*}{\multicolumn{2}{|c|}{$\begin{array}{c}\text { Specificity } \\
\text { IC } 95 \%\end{array}$}} & \multirow{2}{*}{ AUC } & \multirow{2}{*}{$p$} \\
\hline & & & & & & & & \\
\hline & & & & & & & & \\
\hline$<23$ & 51 & 0 & \multicolumn{2}{|c|}{$98.1 \%$} & \multicolumn{2}{|c|}{$100.0 \%$} & 0.9993 & \\
\hline$\geq 23$ & 1 & 39 & $94.3 \%$ & $101.8 \%$ & $100.0 \%$ & $100.0 \%$ & & \\
\hline CAMCOG & $\mathrm{n}$ & $\mathrm{n}$ & & & & & & $<0.0001$ \\
\hline$<90$ & 47 & 1 & \multicolumn{2}{|c|}{$90.4 \%$} & \multicolumn{2}{|c|}{$97.4 \%$} & 0.9712 & \\
\hline$\geq 90$ & 5 & 38 & $82.4 \%$ & $98.4 \%$ & $92.5 \%$ & $102.4 \%$ & & \\
\hline GDS & $\mathrm{n}$ & $\mathrm{n}$ & & & & & & 0.4232 \\
\hline$\geq 3$ & 23 & 14 & \multicolumn{2}{|c|}{$44.2 \%$} & \multicolumn{2}{|c|}{$64.1 \%$} & 0.5754 & \\
\hline$<3$ & 29 & 25 & $30.7 \%$ & $57.7 \%$ & $49.0 \%$ & $79.2 \%$ & & \\
\hline MEEM & $\mathrm{n}$ & $\mathrm{n}$ & & & & & & $<0.0001$ \\
\hline$<29$ & 48 & 7 & \multicolumn{2}{|c|}{$92.3 \%$} & \multicolumn{2}{|c|}{$82.1 \%$} & 0.9522 & \\
\hline$\geq 29$ & 4 & 32 & $85.1 \%$ & $99.6 \%$ & $70.0 \%$ & $94.1 \%$ & & \\
\hline Mendez & $\mathrm{n}$ & $\mathrm{n}$ & & & & & & $<0.0001$ \\
\hline$<19$ & 33 & 4 & \multicolumn{2}{|c|}{$63.5 \%$} & \multicolumn{2}{|c|}{$89.7 \%$} & 0.8119 & \\
\hline$\geq 19$ & 19 & 35 & $50.4 \%$ & $76.5 \%$ & $80.2 \%$ & $99.3 \%$ & & \\
\hline PFAQ & $\mathrm{n}$ & $\mathrm{n}$ & & & & & & $<0.0001$ \\
\hline$\geq 2$ & 46 & 6 & \multicolumn{2}{|c|}{$88.5 \%$} & \multicolumn{2}{|c|}{$84.6 \%$} & 0.9453 & \\
\hline$<2$ & 6 & 33 & $79.8 \%$ & $97.1 \%$ & $73.3 \%$ & $95.9 \%$ & & \\
\hline Shulman & $\mathrm{n}$ & $\mathrm{n}$ & & & & & & $<0.0001$ \\
\hline$<5$ & 43 & 13 & \multicolumn{2}{|c|}{$82.7 \%$} & \multicolumn{2}{|c|}{$66.7 \%$} & 0.8141 & \\
\hline$\geq 5$ & 9 & 26 & $72.4 \%$ & $93.0 \%$ & $51.9 \%$ & $81.5 \%$ & & \\
\hline
\end{tabular}

$\mathrm{AUC}=$ area under the curve. chi-square $/^{*}$ Fisher's exact test.

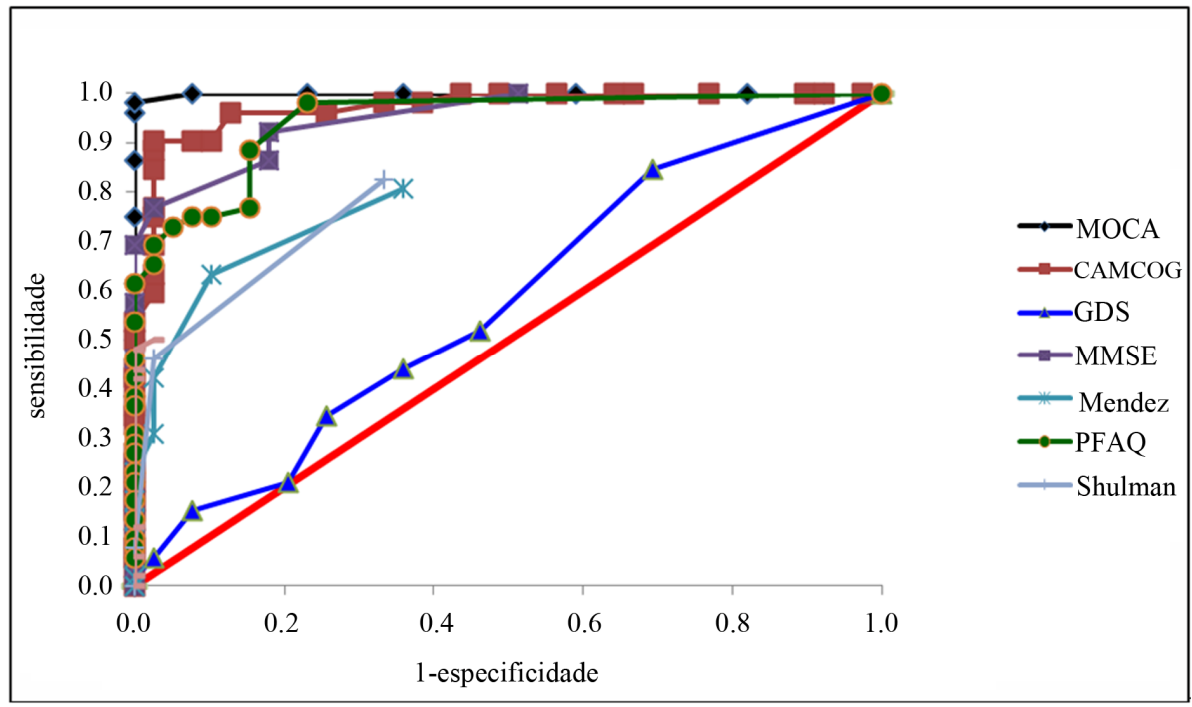

Figure 2. ROC curve to identify AD from NC. 
Table 4. Cutoffs created by BOW ROC methodology to differentiate between AD and MCI.

\begin{tabular}{|c|c|c|c|c|c|c|c|c|}
\hline \multirow{2}{*}{ MOCA } & \multirow{2}{*}{$\frac{\mathrm{AD}}{\mathrm{n}}$} & \multirow{2}{*}{$\frac{\text { MCI }}{n}$} & \multirow{2}{*}{\multicolumn{2}{|c|}{$\begin{array}{c}\text { Sensibility } \\
\text { IC } 95 \%\end{array}$}} & \multirow{2}{*}{\multicolumn{2}{|c|}{$\begin{array}{c}\text { Specificity } \\
\text { IC } 95 \%\end{array}$}} & \multirow{2}{*}{ AUC } & \multirow{2}{*}{$p$} \\
\hline & & & & & & & & \\
\hline$<21$ & 45 & 11 & \multicolumn{2}{|c|}{$86.5 \%$} & \multicolumn{2}{|c|}{$75.6 \%$} & 0.9006 & \\
\hline$\geq 21$ & 7 & 34 & $77.3 \%$ & $95.8 \%$ & $63.0 \%$ & $88.1 \%$ & & \\
\hline CAMCOG & $\mathrm{n}$ & $\mathrm{n}$ & & & & & & $<0.0001$ \\
\hline$<85$ & 36 & 9 & \multicolumn{2}{|c|}{$69.2 \%$} & \multicolumn{2}{|c|}{$80.0 \%$} & 0.8053 & \\
\hline$\geq 85$ & 16 & 36 & $56.7 \%$ & $81.8 \%$ & $68.3 \%$ & $91.7 \%$ & & \\
\hline GDS & $\mathrm{n}$ & $\mathrm{n}$ & & & & & & 0.5464 \\
\hline$\geq 4$ & 18 & 13 & \multicolumn{2}{|c|}{$34.6 \%$} & \multicolumn{2}{|c|}{$71.1 \%$} & 0.4968 & \\
\hline$<4$ & 34 & 32 & $21.7 \%$ & $47.5 \%$ & $57.9 \%$ & $84.4 \%$ & & \\
\hline MEEM & $\mathrm{n}$ & $\mathrm{n}$ & & & & & & $<0.0001$ \\
\hline$<26$ & 36 & 11 & \multicolumn{2}{|c|}{$69.2 \%$} & \multicolumn{2}{|c|}{$75.6 \%$} & 0.791 & \\
\hline$\geq 26$ & 16 & 34 & $56.7 \%$ & $81.8 \%$ & $63.0 \%$ & $88.1 \%$ & & \\
\hline Mendez & $\mathrm{n}$ & $\mathrm{n}$ & & & & & & 0.0015 \\
\hline$<19$ & 33 & 14 & \multicolumn{2}{|c|}{$63.5 \%$} & \multicolumn{2}{|c|}{$68.9 \%$} & 0.6865 & \\
\hline$\geq 19$ & 19 & 31 & $50.4 \%$ & $76.5 \%$ & $55.4 \%$ & $82.4 \%$ & & \\
\hline PFAQ & $\mathrm{n}$ & $\mathrm{n}$ & & & & & & $<0.0001$ \\
\hline$\geq 6$ & 38 & 11 & \multicolumn{2}{|c|}{$73.1 \%$} & \multicolumn{2}{|c|}{$75.6 \%$} & 0.8026 & \\
\hline$<6$ & 14 & 34 & $61.0 \%$ & $85.1 \%$ & $63.0 \%$ & $88.1 \%$ & & \\
\hline Shulman & $\mathrm{n}$ & $\mathrm{n}$ & & & & & & 0.0404 \\
\hline$<5$ & 43 & 29 & \multicolumn{2}{|c|}{$82.7 \%$} & \multicolumn{2}{|c|}{$35.6 \%$} & 0.6983 & \\
\hline$\geq 5$ & 9 & 16 & $72.4 \%$ & $93.0 \%$ & $21.6 \%$ & $49.5 \%$ & & \\
\hline
\end{tabular}

$\mathrm{AUC}=$ area under the curve. chi-square $/{ }^{*}$ Fisher's exact test.

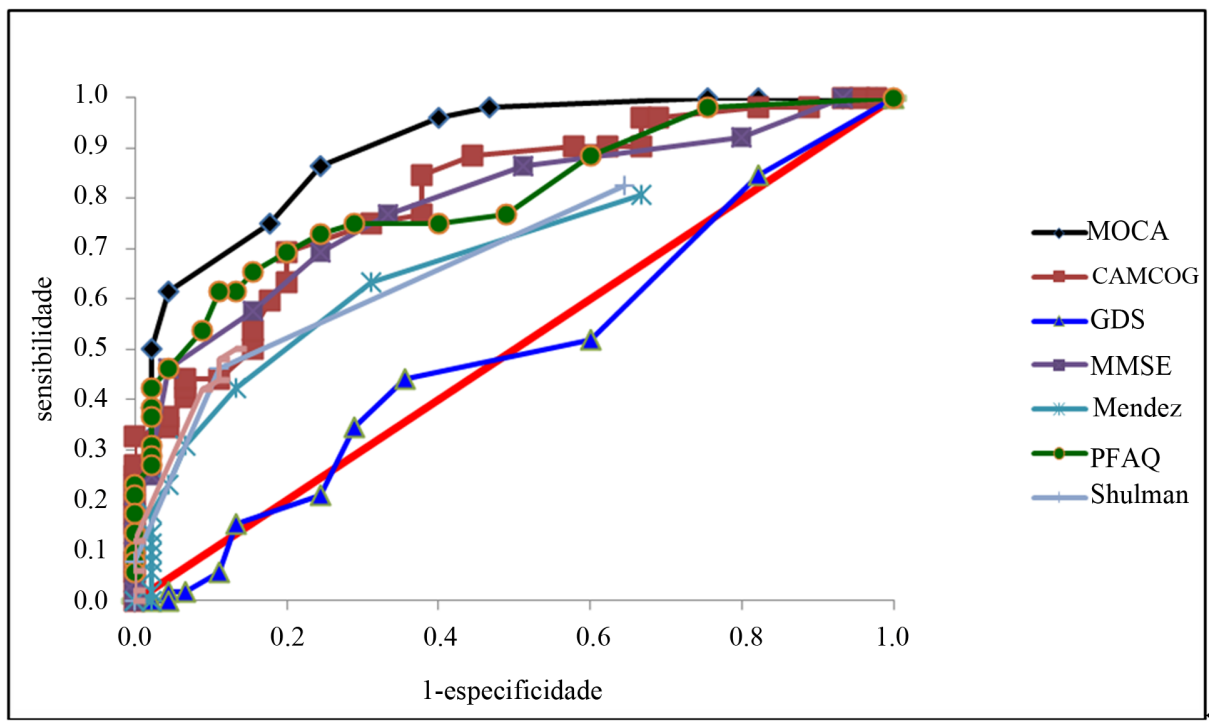

Figure 3. ROC curve to identify MCI from AD. 
Table 5. Risk factor to diferentiate AD from MCI.

\begin{tabular}{ccccc}
\hline Variable & OR & \multicolumn{2}{c}{ IC 95\% } & $\boldsymbol{p}$ \\
\hline MoCA $<21$ & 15.4 & 4.6 & 52.6 & $<\mathbf{0 . 0 0 0 1}$ \\
PFAQ $\geq 6$ & 8.1 & 2.4 & 27.4 & $\mathbf{0 . 0 0 0 7}$ \\
VF animals version & 5.2 & 1.3 & 21.9 & $\mathbf{0 . 0 2 3 2}$ \\
\hline
\end{tabular}

$[17,20,22,23]$. When compared to the MMSE (one of the most widely used screening instruments worldwide) MoCA has more memory items in the assessment, and includes aspects of executive function and a more structured language subitem $[7,20]$. In this research it became clear the best diagnostic accuracy of the MoCA compared to MMSE, CAMCOG, VF and CDT which confirms other mentioned studies above. Other researches also indicate the effectiveness of MoCA as a tool to aid in the differential diagnosis of MCI. Dong (2012) analyzed 230 elderly patients with $\mathrm{MCI}$ and their results showed that the MoCA showed an area under the curve significantly higher when compared to MMSE, respectively with 0.92 and 0.84 indexes. This information corroborates the data of this research where detection of the three diagnostic groups was evaluated by MoCA better than the other cognitive instruments.

Nasreddine (2005) presents a discussion of MoCA considering educational level and suggests cutoff points to subjects with more than 12 years of education and the present study analyses elderly with more than five years of education and the data presented for elderly with more than 5 years of educational level points out that MoCA has better diagnosis accuracy in differentiating $\mathrm{MCI}$ and $\mathrm{AD}$ from $\mathrm{NC}$ at this educational level. Hence, the results of present research extends validity of MoCA to differentiate diagnostic groups with patients that presents lower educational levels than already studied in literature.

Another study that strengthens the hypothesis that the $\mathrm{MoCA}$ is an effective tool for the diagnosis of cognitive impairment was conducted by Markwick (2012) observing that, even in patients with cognitive impairment, the MMSE were normal while MoCA scores pointed to decline. The results pointed evident decline in the subtests of MoCA, and the conclusion reached was that MoCA appears to be a more sensitive screening tool for early detection of cognitive decline. This data is consistent with findings in this study where the MoCA was the test with higher sensitivity and specificity in differentiating $\mathrm{MCI}$ cases from $\mathrm{AD}$ and $\mathrm{NC}$. The educational level also reinforces the hypothesis of a better performance in the MoCA compared to other instruments, since the sample corresponds to elderly people over five years of study.

Siedlecki (2009) argues that cognitive reserve is strongly correlated with executive functions. Because it is a screening test that covers key aspects of cognition and allows assessment of executive functions, MoCA has presented itself as an effective tool for elderly high educational level and that presents mild cognitive decline.

The present research shows an increased risk for $\mathrm{AD}$ when patients scoring below 21 points in MoCA, presenting more than 6 points in PFAQ and also submit a score less than 14 points in $\mathrm{FV}$ test animals version. This information corroborates the researches of Amieva (2008) and Argimon and Stein (2005) that discusses language as a marker for cognitive decline. The results with the Pearson correlation pointed to a strong coefficient between MoCA and other instruments already validated and widely used in Brazil. CAMCOG, MMSE and MoCA presented a correlation equal to 0.81 and 0.86 , respectively. Data from this study show a stronger correlation when compared to the study of Memória, Yassuda, Nakano e Forlenza (2012) who found a correlation of the MoCA, MMSE and CAMCOG equal to 0.82 and 0.74 , respectively. The robust and significant correlation between the MMSE, CDT, CAMCOG and FV suggests that the MoCA seems to be an appropriate test to be applied in the elderly with more than 5 years of study and the results of present study suggest that it is better than all other in predicting demential frames and MCI.

\section{CONCLUSION}

The results presented suggest that MoCA test proved to have predictive value to differentiate $\mathrm{NC}, \mathrm{MCI}$ and AD. It seems a good screening tool for mild cognitive impairment among elderly with less than 5 years of schooling in Brazil. One limiting factor for this study was the small number of patients and be included only elderly over 5 years of schooling. Studies with larger samples are needed to further validate the test also for elderly people with low education.

\section{ACKNOWLEDGEMENTS}

The authors acknowledge research funding from Fundação de Amparo à Pesquisa do Estado de São Paulo-FAPESP (contract number 2011/15133-0).

\section{REFERENCES}

[1] Neri, A.L. (2007). Qualidade de vida na velhice e subjetividade. In: Neri, A.L., Ed., Qualidade de Vida na Velhice: Enfoque Multidisciplinar. Editora Alínea, Campinas, 13-62.

[2] Quinn, A. (2008) Health, aging and cities. Journal of Urban Health, 85, 151-153.

http://dx.doi.org/10.1007/s11524-008-9268-9

[3] Almeida, O.P. (1998) Queixa de problemas com a memória e o diagnóstico de demência. Arquivos de Neurop- 
siquiatria, 56, 412-418. http://dx.doi.org/10.1590/S0004-282X1998000300010

[4] Argimon, I.I.L. and Stein, L.M. (2005) Habilidade cognitivas em indivíduos muito idosos: Um estudo longitudinal. Cadernos de Saúde Pública, 21, 64-72. http://dx.doi.org/10.1590/S0102-311X2005000100008

[5] Cooper, D.B. (2001) Effects of practice on category fluency in Alzheimer's disease. The Clinical Neuropsychologist, 15, 125-128. http://dx.doi.org/10.1076/clin.15.1.125.1914

[6] Brucki, S.M.D., Nitrini, R., Caramelli, P., Bertolucci, P.H.F. and Okamoto, I. (2003) Sugestões para o uso do mini-exame do estado mental no Brasil. Arquivos de Neuropsiquiatra, 61, 777-781. http://dx.doi.org/10.1590/S0004-282X2003000500014

[7] Cecato, J.F., Martinelli, J.E., Bartholomeu, L.L., Basqueira, A.P., Yassuda, M.S. and Aprahamian, I. (2010) Verbal behavior in Alzheimer's disease patients: Analysis in repetition phrases. Dementia \& Neuropsychologia, 4, 202-206.

[8] Mansur, D.M., Sliwinski, M., Lipton, R.B., Blau, A.D. and Crystal, H.A. (1994) Neuropsychological prediction of dementia and the absence of dementia in healthy elderly persons. Neurology, 44, 1427-1432. http://dx.doi.org/10.1212/WNL.44.8.1427

[9] Morris, J.C. (2001) Mild cognitive impairment represents early-stage Alzheimer's disease. Archives of Neurology, 58, 397-405. http://dx.doi.org/10.1001/archneur.58.3.397

[10] Rahman, T.T. and Gaafary, M.M. (2009) Montreal cognitive assessment Arabic version: Reliability and validity prevalence of mild cognitive impairment among elderly attending geriatric clubs in Cairo. Geriatrics \& Gerontology International, 9, 54-61. http://dx.doi.org/10.1111/j.1447-0594.2008.00509.x

[11] Petersen, R.C., Stevens, J., Ganguli, M., Tangalos, E.G., Cummings, J. and DeKosky, S.T. (2001) Pratice parameter: Early detection of dementia: Mild cognitive impairment. Neurology, 56, 1133-1142. http://dx.doi.org/10.1212/WNL.56.9.1133

[12] Freitas, S., Simões, M.R., Alves, L. and Santana, I. (2013) Montreal cognitive assessment: Validation study for mild cognitive impairment and Alzheimer disease. Alzheimer Disease and Associated Disorders, 27, 37-43.

[13] Dong, Y. (2012) The Montreal cognitive assessment is superior to the mini-mental state examination in detecting patients at higher risk of dementia. International Psychogeriatrics, 24, 1749-1755. http://dx.doi.org/10.1017/S1041610212001068

[14] Freitas, S., Simões, M.R., Martins, C., Vilar, M. and Santana, I. (2010) Estudos de adaptação do Montreal cognitive assessment (MoCA) para a população portuguesa. Avaliação Psicológica, 9, 345-357.

[15] Mendez, M.F., Ala, T. and Underwood, K. (1992) Development of scoring criteria for the clock drawing task in Alzheimer's disease. Journal of the American Geriatrics Society, 40, 1095-1099.

[16] McKhann, G.M. (2011) The diagnosis of dementia due to Alzheimer's disease: Recommendations from the na- tional institute on aging-Alzheimer's association workgroups on diagnostic guidelines for Alzheimer's disease. Alzheimer's \& Dementia, 7, 263-269. http://dx.doi.org/10.1016/j.jalz.2011.03.005

[17] Markwick, A., Zamboni, G. and de Jager, C.A. (2012) Profiles of cognitive subtest impairment in the Montreal cognitive assessment (MoCA) in a research cohort with normal mini-mental state examination (MMSE) scores. Journal of Clinical and Experimental Neuropsychology, 34, 750-757. http://dx.doi.org/10.1080/13803395.2012.672966

[18] World Health Organization (1992) International classification of diseases. Mental and behavioral disorders. World Health Organization, Geneva.

[19] Amieva, H. (2008) Prodromal Alzheimer's disease: Successive emergence of the clinical symptoms. Annals of Neurology, 64, 492-498. http://dx.doi.org/10.1002/ana.21509

[20] Bottino, C.M.C. and Moreno, M.D.P.Q. (2006) Comprometimento cognitivo leve: Critérios diagnósticos e validade clínica. In: Bottino, C.M.C., Laks, J., Blay, S.L., Eds., Demência e Transtornos Cognitivos em Idosos. Guanabara Koogan, Rio de Janeiro, 31-37.

[21] Nitrini, R. (2009) Prevalence of dementia in Latin America: A collaborative study of population-based cohorts. International Psychogeriatrics, 21, 622-630. http://dx.doi.org/10.1017/S1041610209009430

[22] Memória, C.M., Yassuda, M.S., Nakano, E.Y. and Forlenza, O.V. (2012) Brief screening for mild cognitive impairmente: Validation of Brazilian version of the Montreal cognitive assessment. International Journal of Geriatric Psychiatry, 28, 34-40.

[23] Nasreddine, Z.S. (2005) The Montreal cognitive assessment: A brief screening tool for mild cognitive impairment. Journal of the American Geriatrics Society, 53, 695-699. http://dx.doi.org/10.1111/j.1532-5415.2005.53221.x

[24] Pfeffer, R.I., Kurosaki, T.T., Harrah Jr., C.H., Chance, J.M. and Filos, S. (1982) Measurement of functional activities in older adults in the community. Journal of Gerontology, 37, 323-329. http://dx.doi.org/10.1093/geronj/37.3.323

[25] Roth, M. (1986) CAMDEX. A standardised instrument for the diagnosis of mental disorder in the elderly with special reference to the early detection of dementia. The British Journal of Psychiatry, 149, 698-709. http://dx.doi.org/10.1192/bjp.149.6.698

[26] Shulman, K.I., Gold, D.P., Cohen, C.A. and Zucchero, C.A. (1993) Clock-drawing and dementia in the community: A longitudinal study. International Journal of Geriatric Psychiatry, 8, 487-496. http://dx.doi.org/10.1002/gps.930080606

[27] Sarmento, A.R.L. (2009) Apresentação e aplicabilidade da versão brasileira da MoCA (Montreal cognitive assessment) para rastreio de comprometimento cognitivo leve [MD]. Escola Paulista de Medicina da Universidade Federal de São Paulo, São Paulo.

[28] Tsai, C.F., Lee, W.J., Wang, S.J., Shia, B.C., Nasreddine, 
Z. and Fuh, J.L. (2011) Psychometrics of the Montreal cognitive assessment (MoCA) and its subscales: Validation of the Taiwanese version of the MoCA and an item response theory analysis. International Psychogeriatrics, 12, $1-8$.
[29] Yesavage, J.A. (1983) Development and validation of a geriatric depression screening scale: A preliminary report. Journal of Psychiatric Research, 17, 37-49. http://dx.doi.org/10.1016/0022-3956(82)90033-4 